\title{
Clinical and Multimodal Imaging Findings and Risk Factors for Ocular Involvement in a Presumed Waterborne Toxoplasmosis Outbreak, Brazil ${ }^{1}$
}

Camilo Brandão-de-Resende, Helena Hollanda Santos, Angel Alessio Rojas Lagos, Camila Munayert Lara, Jacqueline Souza Dutra Arruda, Ana Paula Maia Peixoto Marino, Lis Ribeiro do Valle Antonelli, Ricardo Tostes Gazzinelli, Ricardo Wagner de Almeida Vitor, Daniel Vitor Vasconcelos-Santos

\section{Medscape ACTIVITY}

In support of improving patient care, this activity has been planned and implemented by Medscape, LLC and Emerging Infectious Diseases. Medscape, LLC is jointly accredited by the Accreditation Council for Continuing Medical Education (ACCME), the Accreditation Council for Pharmacy Education (ACPE), and the American Nurses Credentialing Center (ANCC), to provide continuing education for the healthcare team

Medscape, LLC designates this Journal-based CME activity for a maximum of 1.00 AMA PRA Category 1 Credit(s) ${ }^{\mathrm{TM}}$. Physicians should claim only the credit commensurate with the extent of their participation in the activity.

Successful completion of this CME activity, which includes participation in the evaluation component, enables the participant to earn up to 1.0 MOC points in the American Board of Internal Medicine's (ABIM) Maintenance of Certification (MOC) program. Participants will earn MOC points equivalent to the amount of CME credits claimed for the activity. It is the CME activity provider's responsibility to submit participant completion information to ACCME for the purpose of granting ABIM MOC credit.

All other clinicians completing this activity will be issued a certificate of participation. To participate in this journal CME activity: (1) review the learning objectives and author disclosures; (2) study the education content; (3) take the post-test with a $75 \%$ minimum passing score and complete the evaluation at http://www.medscape.org/journal/eid; and (4) view/print certificate. For CME questions, see page 3121.

Release date: November 19, 2020; Expiration date: November 19, 2021

Learning Objectives

Upon completion of this activity, participants will be able to:

- Describe clinical and multimodal imaging findings at presentation and prevalence of and risk factors for ocular involvement in toxoplasmosis

reported during an outbreak in 2015 in Gouveia, Brazil

- Determine recurrences and complications of toxoplasmosis reported during an outbreak in 2015 in Gouveia, Brazil

- Identify clinical implications of findings, course, and risk factors for ocular involvement in toxoplasmosis reported during an outbreak in 2015 in Gouveia, Brazil.

CME Editor

Amy J. Guinn, BA, MA, Copyeditor, Emerging Infectious Diseases. Disclosure: Amy J. Guinn, BA, MA, has disclosed no relevant financial relationships.

\section{CME Author}

Laurie Barclay, MD, freelance writer and reviewer, Medscape, LLC. Disclosure: Laurie Barclay, MD, has disclosed no relevant financial relationships.

\section{Authors}

Disclosure: Camilo Brandão-de-Resende, BEng, MD, PhD, and Daniel Vitor Vasconcelos-Santos, MD, PhD, have disclosed the following relevant financial relationships: co-founder/partner of Alsculapius Medicina Inteligente Ltda. Helena Hollanda Santos, MD, MSc; Angel Alessio Rojas Lagos, PhD; Camila Munayert Lara, MD; Jacqueline Souza Dutra Arruda, MD; Ana Paula Maia Peixoto Marino, PhD; Lis Ribeiro do Valle Antonelli, PhD; Ricardo Tostes Gazzinelli, PhD; and Ricardo Wagner de Almeida Vitor, PhD, have disclosed no relevant financial relationships.

Author affiliations: Universidade Federal de Minas Gerais, Belo Horizonte, Brazil (C. Brandão-de-Resende, H.H. Santos, A.A.R. Lagos, C.M. Lara, J.S.D. Arruda, R.W.A, Vitor, D.V. Vasconcelos-Santos);Centro de Pesquisas René Rachou, Fundação Oswaldo Cruz, Belo Horizonte (A.P.M.P. Marino, L.R.V. Antonelli, R.T. Gazzinelli).

DOI: https://doi.org/10.3201/eid2612.200227

${ }^{1}$ Presented in part at the 2015 American Uveitis Society Fall meeting, November 15, 2014, Las Vegas, Nevada, USA 
In 2015, an outbreak of presumed waterborne toxoplasmosis occurred in Gouveia, Brazil. We conducted a 3-year prospective study on a cohort of 52 patients from this outbreak, collected clinical and multimodal imaging findings, and determined risk factors for ocular involvement. At baseline examination, 12 (23\%) patients had retinochoroiditis; 4 patients had bilateral and 2 had macular lesions. Multimodal imaging revealed 2 distinct retinochoroiditis patterns: necrotizing focal retinochoroiditis and punctate retinochoroiditis. Older age, worse visual acuity, self-reported recent reduction of visual acuity, and presence of floaters were associated with retinochoroiditis. Among patients, persons $\geq 40$ years of age had 5 times the risk for ocular involvement. Five patients had recurrences during follow-up, a rate of $22 \%$ per person-year. Recurrences were associated with binocular involvement. Two patients had late ocular involvement that occurred $\geq 34$ months after initial diagnosis. Patients with acquired toxoplasmosis should have long-term ophthalmic follow-up, regardless of initial ocular involvement.

$\mathrm{T}$ oxoplasmosis is caused by Toxoplasma gondii, an obligate intracellular apicomplexan parasite that infects up to one third of the human population (1-4). Humans are mainly infected by ingesting tissue cysts in undercooked or raw meat or oocysts excreted in cat feces that contaminate water or food (1-4). Ocular disease is the major clinical repercussion in immunocompetent patients; toxoplasmosis is the leading cause of infectious posterior uveitis worldwide and can potentially lead to severe ocular complications $(1,3,5,6)$. Although congenital toxoplasmosis more frequently leads to retinochoroiditis, postnatally acquired infection now is acknowledged as being associated with a large proportion of cases $(2,3,6,7)$. Association between ocular toxoplasmosis and older age is not completely understood (8), but previous studies found increased prevalence of ocular involvement in persons $>30$ years of age $(9,10)$.

Toxoplasmosis outbreaks are good opportunities to clarify clinical aspects of this complex disease because patients are infected at known times, by similar routes, and presumably by parasites of the same genotype (11-19). In 2015, an outbreak of presumed waterborne toxoplasmosis was reported in Gouveia, a small city of $\approx 10,000$ inhabitants in the center of the state of Minas Gerais in southeastern Brazil (20). Municipal, state, and federal health authorities investigated several cases of fever, malaise, weight loss, and lymphadenopathy. Recent toxoplasmic infection was eventually confirmed in 52 cases. All patients had the disease after drinking water from a single, presumably contaminated, source (20).
We performed complete ophthalmic examination and multimodal fundus imaging evaluation on all 52 patients. The objective of this study was to describe clinical and multimodal imaging findings and determine the prevalence of ocular involvement, incidence of recurrences and complications, and to analyze risk factors for ocular involvement in this cohort.

\section{Methods}

We used a prospective cohort approach to address our main goal. The study was approved by institutional review boards of René Rachou Research Center, Oswaldo Cruz Foundation (CAAE no. 37614314.7.3001.5091), and Federal University of Minas Gerais (CAAE no. 37614314.7.3001.5149). All patients provided written informed consent.

We defined a case as illness in a person in the city of Gouveia with a history of fever, headache, lymphadenopathy, asthenia, or myalgia during February 12-May 18, 2015. From 5,276 local health charts, a task force comprised of municipal, state, and federal health authorities identified 201 persons suspected of meeting case definition criteria. Before confirmation of toxoplasmosis, differential diagnosis was made with consultation of an infectious disease specialist and serologic tests for dengue fever, visceral leishmaniasis, and leptospirosis.

We contacted the 201 persons with suspected toxoplasmosis. We were able to reach 151 (75.1\%) persons whom we subsequently interviewed and tested for toxoplasmosis. We defined confirmed cases of acute toxoplasmosis as persons having T. gondii IgM and low avidity IgG on enzyme-linked fluorescence assay by using Vidas Toxo IgM, IgGII, and IgG avidity assays (bioMérieux, https://www.biomerieux.com).

Among the 151 suspected cases interviewed and tested, $52(34.4 \%)$ had serologic evidence of T. gondii IgM and low avidity IgG, indicating acute toxoplasmosis. We performed a complete ophthalmic examination on each of the 52 case-patients, including assessment of best-corrected visual acuity (VA), applanation tonometry, slit-lamp examination (SLE; biomicroscopy), and indirect ophthalmoscopy. All case-patients also underwent multimodal imaging evaluation, including fundus photography, reflectances, fundus autofluorescence, and spectral-domain optical coherence tomography (SD-OCT). For patients with confirmed ocular involvement, we also performed fluorescein angiography. We determined prevalence and incidence of ocular changes and clinical characteristics on the basis of clinical and multimodal imaging findings. All patients with ocular involvement received standard therapy for 35-45 
days, which consisted of sulfadiazine $(1 \mathrm{~g} 4 \times / \mathrm{d})$, pyrimethamine $(25-50 \mathrm{mg} / \mathrm{d})$, folinic acid $(7.5 \mathrm{mg} / \mathrm{d})$, and prednisone (40-60 mg/d). One patient was allergic to sulfa and was switched from sulfadiazine to clindamycin $300 \mathrm{mg} 4 \times / \mathrm{d}$. Complete blood counts were monitored at baseline and every 2 weeks during treatment.

For 3 years, we conducted follow-up examinations on case-patients at 5-8-month intervals and conducted the same ophthalmic examination protocol periodically. We reexamined case-patients with active primary or recurrent retinochoroiditis 3-6 weeks after therapy, or more often, if needed. We defined severe ocular involvement as binocular or macular involvement, or extensive necrotizing retinochoroiditis of $>3$ disk diameter (DD).

We prospectively collected and stored in an electronic database clinical and ophthalmological data, including symptoms, best-corrected VA, applanation tonometry, SLE, indirect ophthalmoscopy, and multimodal imaging. We assessed best-corrected VA by using an early treatment of diabetic retinopathy study chart and reported results in logarithm of the minimum angle of resolution (logMAR) scale. Previous studies suggested increased prevalence of ocular involvement among patients $\geq 30$ years of age and among patients $\geq 50$ years of age $(9,10)$. We also analyzed age $\geq 40$ years at time of infection as a potential risk factor for occurrence and severity of ocular involvement.

We defined the time of primary infection for each case-patient as the time of ocular or systemic symptom onset. To calculate time intervals among persons with new active retinochoroidal lesions during follow-up, we assumed eye disease occurred when patients first noted ocular symptoms. For casepatients without ocular symptoms, we assumed eye disease occurred when consistent retinochoroidal lesions were identified. Among case-patients who displayed new retinochoroidal scars during followup exams, we assumed eye disease occurred when ocular symptoms first were perceived; if the casepatient did not notice any ocular symptoms, we assumed eye disease occurred in the time between the prior ocular examination and identification of the scar. We also noted the first instance of retinochoroidal recurrences in either eye.

We performed statistical analyses by using $\mathrm{R}$ version 3.5.2 (21) by nonparametric methods and considered $\mathrm{p}<0.05$ statistically significant. We used Mann-Whitney-Wilcoxon test to compare continuous variables, including age, length of follow-up, and VA at baseline. We used the mid-p exact test to compare proportions between subgroups, such as age $\geq 40$ years, sex, and presence of underlying conditions and symptoms. We reported continuous variables as median (interquartile range [IQR]) and proportions as no. (\%). We estimated the $95 \% \mathrm{CI}$ of relative risks by using a maximum-likelihood estimator and described the follow-up by using the rate of recurrence per person-year (22), rate of recurrence per personmonth, and Kaplan-Meier survival plot (23). We estimated survival probability and cumulative risk for ocular involvement and ocular recurrence by using the Kaplan-Meier method and compared results by using a log-rank test $(24,25)$.

\section{Results}

\section{Baseline Examination}

All 52 patients with serologic evidence of acute toxoplasmosis underwent a baseline examination in the first 4 months after onset of systemic symptoms; 40 (77\%) patients had a baseline exam within the first month (Table 1). Median age at infection was 34 years (IQR 27-40 years); 8 (15.4\%) patients were female and $44(84.6 \%)$ were male. The most common systemic signs or symptoms were fever $(52 / 52 ; 100 \%)$, headache $(33 / 52 ; 63 \%)$, myalgia (30/52; 58\%), and lymphadenopathy $(8 / 52 ; 15 \%)$. Ocular symptoms were reported by 17 (32.6\%) patients, among whom 9 (52.9\%) reported recent VA decrease, 8 reported eye pain $(47 \%)$, and $3(17.6 \%)$ reported floaters.

At baseline, $12(23 \%)$ patients had retinochoroiditis (Figure 1), 4 (33\%) of whom had bilateral involvement and 2 (17\%) of whom had macular involvement. Necrotizing lesions or scars were found in 10 (58\%) patients; subtle punctate active lesions were found in 4 $(33 \%)$ patients. Among 4 (33\%) patients, we observed multiple necrotizing lesions or multifocal punctate active lesions in different retinal quadrants (Table 2). SLE revealed all 12 patients with toxoplasmic retinochoroiditis had inflammatory cells in the anterior vitreous; however, only 3 (25\%) had inflammatory cells in the anterior chamber with standardization of uveitis nomenclature (SUN) grade ranging from $0.5+$ to $3+$. Intraocular pressure was within normal limits in all but 1 patient with granulomatous keratic precipitates and SUN of 3+ in the anterior chamber. Two $(17 \%)$ patients with retinochoroiditis did not report any eye symptoms (Table 3 ).

We observed other fundus changes among patients with confirmed acute toxoplasmosis but without ocular involvement. One patient had unspecific focal retinal pigment epithelium (RPE) hyperplasia in 1 eye; a patient with nyctalopia had 
Table 1. Characteristics and ocular signs and symptoms among patients with confirmed acute toxoplasmosis infection at baseline examination, Brazil ${ }^{*}$

\begin{tabular}{|c|c|c|c|c|}
\hline Characteristics & Total, $n=52$ & $\begin{array}{l}\text { No ocular involvement, } \\
\qquad \mathrm{n}=40\end{array}$ & $\begin{array}{l}\text { Ocular involvement, } \\
\qquad \mathrm{n}=12\end{array}$ & $\mathrm{p}$ value \\
\hline Age at infection, y, median (IQR)† & $34(27-40)$ & $32(22-38)$ & $43(40-47)$ & $<0.01$ \\
\hline$\geq 40$ years of age $\dagger$ & $14(27)$ & $6(15)$ & $9(75)$ & $<0.01$ \\
\hline \multicolumn{5}{|l|}{ Sex } \\
\hline M & $44(84.6)$ & $33(82.5)$ & $11(91.7)$ & 0.50 \\
\hline $\mathrm{F}$ & $8(15.4)$ & $7(17.5)$ & $1(8.3)$ & 0.50 \\
\hline Follow-up length, mo, median (IQR) & $36(19-36)$ & $36(12-36)$ & $35(24-37)$ & 0.32 \\
\hline \multicolumn{5}{|l|}{ Underlying conditions } \\
\hline Arterial hypertension & $7(13.5)$ & $4(10.0)$ & $3(25.0)$ & 0.23 \\
\hline Diabetes mellitus & $1(1.9)$ & 0 & $1(8.3)$ & 0.23 \\
\hline \multicolumn{5}{|l|}{ General signs and symptoms } \\
\hline Fever & $49(94.2)$ & $38(95.0)$ & $11(91.7)$ & 0.68 \\
\hline Headache & $33(63.5)$ & $25(62.5)$ & $8(66.7)^{\prime}$ & 0.81 \\
\hline Myalgia & $30(57.7)$ & $22(55.0)$ & $8(66.7)$ & 0.50 \\
\hline Lymphadenopathy & $8(15.4)^{\prime}$ & $7(17.5)$ & $1(8.3)$ & 0.50 \\
\hline \multicolumn{5}{|l|}{ Ocular signs and symptoms } \\
\hline VA at baseline, logMAR, median (IQR)†‡ & $0.0(0.0-0.0)$ & $0.0(0.0-0.0)$ & $0.1(0.0-0.6)$ & 0.01 \\
\hline Eye pain & $8(15.4)$ & $5(12.5)$ & $3(25.0)$ & 0.33 \\
\hline Self-reported recent reduction of VA† & $10(19.2)$ & $1(2.5)$ & $9(75.0)$ & $<0.01$ \\
\hline Floaters $†$ & $3(5.7)$ & 0 & $3(25.0)$ & 0.01 \\
\hline \multicolumn{5}{|c|}{$\begin{array}{l}\text { "Values are no. (\%), except as indicated. Mann-Whitney-Wilcoxon test was used to compare continuous and the mid-p exact tests for proportions } \\
\text { between subgroups. IQR, interquartile range; logMAR, logarithm of the Minimum Angle of Resolution scale; VA, visual acuity. } \\
\text { †Statistical significant at } \alpha=5 \% \text {. } \\
\ddagger \text { For visual acuity baseline, binocular involvement was considered the worst VA. }\end{array}$} \\
\hline
\end{tabular}

bilateral optic disc pallor, vascular attenuation and RPE changes consistent with retinitis pigmentosa; another patient with severe systemic arterial hypertension had bilateral nerve-fiber layer infarcts. One patient with ocular toxoplasmosis in 1 eye had findings consistent with Leber miliary aneurysms in the contralateral eye.

Among the 12 patients with ocular disease at baseline, 9 (75\%) had severe ocular involvement, defined by binocular, macular, or extensive ( $>3 \mathrm{DD}$ ) necrotizing retinochoroiditis. Among 9 patients with severe ocular involvement, the median age was 43 years (IQR 40-47 years); among 3 patients without severe ocular involvement the median age was 31 years (IQR 29-38 years), but the difference was not statistically significant $(p=0.14)$.

Age, self-reported recent reduction of VA, presence of floaters, and greater reduction in VA were associated with ocular involvement at baseline (Table 1).
Among patients with ocular involvement, the median age at infection was 43 years (IQR 40-47 years) vs. 31 years (IQR 22-38 years) for patients without ocular involvement $(\mathrm{p}=0.02) ; 9(75 \%)$ patients with ocular involvement were $\geq 40$ years of age at infection compared with $6(15 \%)$ patients without ocular involvement (relative risk $[R R]=5.0,95 \%$ CI 2.2-11.2; $p<0.01$ ). Among these same subgroups, median logMAR VA at examination was 0.1 (IQR 0.0-0.6) for patients with ocular involvement compared with $0.0(0.0-0.0)$ for patients without ocular involvement $(p=0.01)$.

Multimodal imaging revealed 2 distinct patterns of active retinochoroiditis: the typical pattern of focal necrotizing retinochoroiditis and punctate retinochoroiditis. Necrotizing retinochoroiditis subsequently left a variably pigmented scar and was more extensive in some cases, simulating a viral retinitis (Figure 2). Punctate retinochoroiditis displayed a much more subtle pattern, which was not seen as

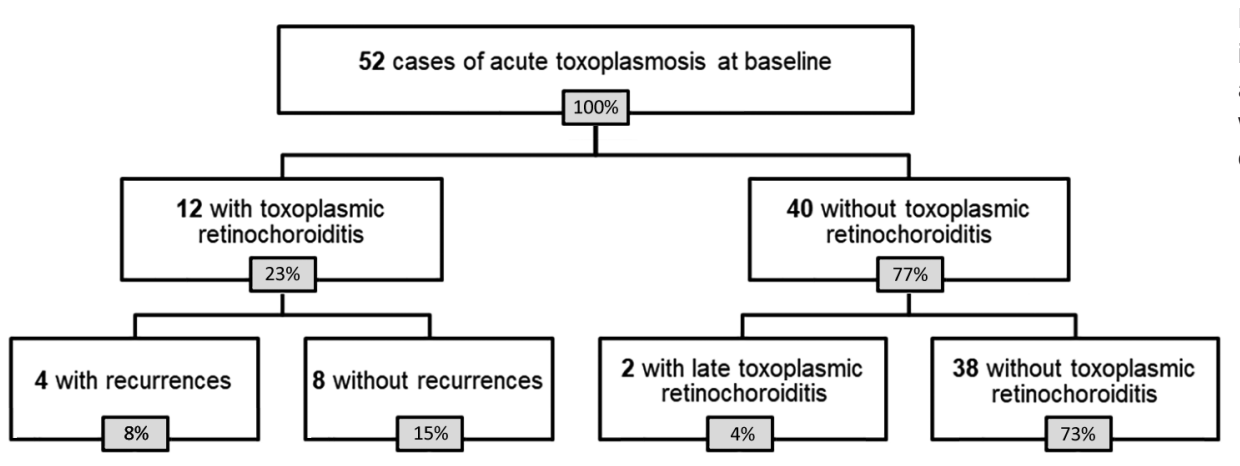

Figure 1. Flowchart of patients in study of ocular involvement associated with a presumed waterborne toxoplasmosis outbreak, Brazil. 
Table 2. Characterization of patterns of retinochoroiditis seen in multimodal imaging among patients with toxoplasmosis treated with antiparasitic drugs and oral corticosteroids, Brazil ${ }^{*}$

\begin{tabular}{lcc}
\hline $\begin{array}{l}\text { Type of lesion, fundus imaging } \\
\text { modality }\end{array}$ & Active phase, before treatment & Patterns of retinochoroiditis \\
\cline { 2 - 3 } $\begin{array}{c}\text { Focal necrotizing retinochoroiditis } \\
\text { Fundus photo or examination }\end{array}$ & $\begin{array}{c}\text { Dense focal retinal whitening with indistinct } \\
\text { borders, associated with overlying vitreous } \\
\text { haze }\end{array}$ & $\begin{array}{c}\text { Initially hypopigmented retinochoroidal scar, but } \\
\text { frequently evolving with variable degree of } \\
\text { pigmentation and subretinal fibrosis or preretinal } \\
\text { gliosis }\end{array}$ \\
SD-OCT & $\begin{array}{c}\text { Focal full-thickness hyper-reflectivity } \\
\text { and disorganization of retinal layers } \\
\text { indicating necrotizing retinitis; surrounding } \\
\text { retinal thickening, signaling edema; numerous } \\
\text { overlying hyper-reflective dots at the vitreous } \\
\text { indicating vitreal inflammatory cell exudate; and } \\
\text { underlying fusiform choroidal thickening, with }\end{array}$ & $\begin{array}{c}\text { Disorganization of retinal architecture; hyper- } \\
\text { reflectivity at the level of the scar, but without } \\
\text { perilesional retinal thickening; resolution of } \\
\text { choroidal thickening; marked decrease in the } \\
\text { number of overlying vitreal hyper-reflective dots; } \\
\text { and frequent tent-like focal detachment of the } \\
\text { less thickened overlying posterior hyaloid }\end{array}$
\end{tabular}

FAF reflectances Subtle hypo- or hyper-autofluorescence changes at the level of the active lesion; near infrared reflectance can indicate active focus but not as remarkably as red-free reflectance

FFA

\section{Punctate retinochoroiditis \\ Fundus photo or examination}

SD-OCT

FAF reflectances

FFA

Early hypofluorescence, with progressive hyperfluorescence and late leakage at the retinochoroiditis lesion; reactive changes, including hyperfluorescence, of optic disc indicating edema; staining of venular walls, signaling periphlebitis

Multiple subtle, indistinct, or confluent gray-whitish punctate retinal infiltrates with minimal vitreous haze Multifocal hyper-reflectivity at the inner retinal layers, demonstrating retinitis, occasionally extending to deeper layers, with surrounding retinal thickening (edema); numerous overlying hyper-reflective dots indicating vitreal inflammatory cell exudate, along with thickening and shallow detachment of the posterior hyaloid; mild choroidal thickening without apparent major change in reflectivity Subtle hypo- or hyper-autofluorescence changes at the level of the punctate active lesions; near-infrared reflectance can show changes at the area of active foci but not as remarkably as red-free reflectance Progressive but mild hyperfluorescence or late leakage at the site of punctate lesions; reactive changes, including hyperfluorescence of optic disc, demonstrating edema; staining of venular walls indicating periphlebitis
Increased autofluorescence signal in the first weeks, then hypo-autofluorescence at the level of the scar after several months; scars less

clearly delineated by near-infrared than red-free reflectance, but both reveal retinal wrinkling in the presence of epiretinal membrane

Variable window defects and blockage at the

level of the scar; staining in the presence of subretinal fibrosis and epiretinal gliosis
Very subtle changes in retinal reflex, sometimes with minor hypopigmentation, but frequently with no apparent abnormality

Frequent normalization of the retinal architecture, sometimes with mild disruption of outer retinal layers or retinal pigment epithelium; normalization of choroidal thickening; marked decrease in the number of overlying vitreal hyper-reflective dots and frequent tent-like focal detachment of the less-thickened overlying posterior hyaloid

Autofluorescence and reflectance changes are minimal or absent

Normal or showing minimal punctate window defects easily on fundus examination, but was nicely delineated by SD-OCT (Figure 3). All 12 patients with toxoplasmic retinochoroiditis promptly responded to antiparasitic treatment; 11 received standard therapy with sulfadiazine, pyrimethamine, and folinic acid, supplemented with oral prednisone; 1 had clindamycin instead of sulfadiazine because of sulfa allergy. All 12 patients had resolution of intraocular inflammation within 5-6 weeks. However, the pattern of retinochoroiditis resolution differed between patients with focal necrotizing retinochoroiditis and those with punctate retinochoroiditis (Table 2).

\section{Follow-up Examinations}

Among all 52 patients in the cohort, the median length of follow-up after infection was 36 months (IQR 19-36 months); most $(47 ; 90 \%)$ patients were followed for $>6$ months. Among the 12 patients with ocular involvement at baseline examination, $5(42 \%)$ had recurrent retinochoroiditis during 
follow-up examinations (Figure 1). The median time for first recurrence was 11 months after starting standard therapy for the first episode of ocular involvement, and the 5 patients had recurrences at $2,9,11,12$, and 22 months (Table 3). All 5 reported adequate treatment adhesion.

Rate of recurrence of retinochoroiditis among the 12 patients with ocular involvement at baseline was $22 \%$ per person-year ( $1.8 \%$ per person-month). All patients with binocular involvement $(n=4)$ had recurrent lesions during the follow-up period compared with only $13 \%(1 / 8)$ of patients with monocular involvement $(\mathrm{RR}=8.0,95 \%$ CI 1.3-50.0; $\mathrm{p}$ $=0.01$ ). Rate of recurrence was $8.5 \%$ per personmonth among patients with binocular involvement and $0.4 \%$ per person-month among the patients

\begin{tabular}{|c|c|c|c|c|c|c|}
\hline \multirow{2}{*}{$\begin{array}{l}\text { Age, } \\
\text { y/sex }\end{array}$} & \multicolumn{3}{|c|}{ Baseline eye examination } & \multirow[b]{2}{*}{ Follow-up findings } & \multirow[b]{2}{*}{ Complications } & \multirow{2}{*}{$\begin{array}{l}\text { Last VA, } \\
\text { mo; result }\end{array}$} \\
\hline & $\mathrm{RC}$ & Right & Left & & & \\
\hline $38 / \mathrm{M} \dagger$ & Bilateral & $\begin{array}{l}\text { VA 0.0; SLE, AV cells and } \\
\text { AC cells }(0.5+/ 4+) ; F E, \\
\text { multifocal PR and } \\
\text { peripheral large FNR }\end{array}$ & $\begin{array}{c}\text { VA 0.0; SLE, AV cells; } \\
\text { FE, PR }\end{array}$ & $\begin{array}{l}1 \text { OD recurrence; month } \\
2, \text { satellite active lesion }\end{array}$ & None & $21 ; 0.0 \mathrm{OU}$ \\
\hline 47/M† & Bilateral & $\begin{array}{l}\text { VA 0.2; SLE, AV cells;FE, } \\
\text { peripheral large FNR }\end{array}$ & $\begin{array}{c}\text { VA 0.0; SLE, AV cells; } \\
\text { FE, multiple } \\
\text { peripheral large FNR }\end{array}$ & $\begin{array}{l}1 \text { OD recurrence; month } \\
22 \text {, new peripheral scar }\end{array}$ & $\begin{array}{l}\text { Month 22, epiretinal } \\
\text { membrane OD }\end{array}$ & $34 ; 0.0 \mathrm{OU}$ \\
\hline $40 / \mathrm{M} \dagger$ & Bilateral & $\begin{array}{l}\text { VA 0.0; SLE, AV cells; } \\
\text { FE, multifocal PR }\end{array}$ & $\begin{array}{l}\text { VA 0.0; SLE, AV cells; } \\
\text { FE, multifocal PR and } \\
\text { peripheral large FNR }\end{array}$ & $\begin{array}{l}\text { Multiple recurrences OU; } \\
\text { months } 11,21, \text { and } 24, \\
\text { active peripheral lesions; } \\
\text { month } 27, \text { active } \\
\text { peripheral lesion OS }\end{array}$ & $\begin{array}{l}\text { Month } 21 \text {, epiretinal } \\
\text { membrane OD; } \\
\text { month } 27 \\
\text { rhegmatogenous } \\
\text { RD OS }\end{array}$ & $\begin{array}{l}36 ; 0.0 \text { OD } \\
\quad 0.8 \text { OS }\end{array}$ \\
\hline $48 / \mathrm{M} \dagger$ & Bilateral & $\begin{array}{l}\text { VA 2.1; SL, EAV cells; } \\
\text { FE, macular FNR }\end{array}$ & $\begin{array}{l}\text { VA 0.3; SLE, AV cells; } \\
\text { FE, peripheral FNR }\end{array}$ & $\begin{array}{l}2 \text { recurrences OS; new } \\
\text { peripheral scar in } \\
\text { months } 12 \text { and } 15\end{array}$ & $\begin{array}{l}\text { Month 9, epiretinal } \\
\text { membrane OD; } \\
\text { month } 34 \text {, epiretinal } \\
\text { membrane OS }\end{array}$ & $\begin{array}{l}34 ; 1.9 \text { OD } \\
0.4 \text { OS }\end{array}$ \\
\hline $43 / \mathrm{M} \dagger$ & Unilateral & $\begin{array}{l}\text { VA 0.0; SLE, normal; FE, } \\
\text { Leber miliary aneurysms }\end{array}$ & $\begin{array}{l}\text { VA } 0.7 ; \text { SLE, fine KP, } \\
\text { AC cells } 2+/ 4+\text {, and } \\
\text { AV cells; FE, } \\
\text { peripheral large FNR }\end{array}$ & - & None & $36 ; 0.1 \mathrm{OS}$ \\
\hline$\overline{27 / M}$ & Unilateral & $\begin{array}{c}\text { VA 0.0; SLE, AV cells; } \\
\text { FE, PR }\end{array}$ & $\begin{array}{l}\text { VA 0.0; normal SLE } \\
\text { and FE }\end{array}$ & - & None & $23 ; 0.0 \mathrm{OD}$ \\
\hline 42/M† & Unilateral & $\begin{array}{c}\text { VA 0.5; SLE, } \\
\text { granulomatous KP, AC } \\
\text { cells }(3+/ 4+), A V \text { cells; } \\
\text { IOP, } 28 \mathrm{mmHg} \text {; FE, } \\
\text { peripheral large FNR }\end{array}$ & $\begin{array}{l}\text { VA 0.0; normal SLE } \\
\text { and FE }\end{array}$ & $\begin{array}{c}1 \text { recurrence OD; month } \\
9, \text { multiple active } \\
\text { peripheral lesions OD }\end{array}$ & $\begin{array}{l}\text { Baseline transient } \\
\text { IOP elevation OD, } \\
28 \mathrm{mmHg}\end{array}$ & $24 ; 0.0 \mathrm{OD}$ \\
\hline$\overline{31 / M}$ & Unilateral & $\begin{array}{l}\text { VA } 0.0 ; \text { normal SLE and } \\
\text { FE }\end{array}$ & $\begin{array}{l}\text { VA 0.0; SLE OS, AV } \\
\text { cells; FE, multiple } \\
\text { peripheral FNR }\end{array}$ & - & None & $8 ; 0.0 \mathrm{OS}$ \\
\hline $50 / \mathrm{M} \dagger$ & Unilateral & $\begin{array}{l}\text { VA 0.5; SLE, AV cells; } \\
\text { FE, peripheral large FNR }\end{array}$ & $\begin{array}{l}\text { VA 0.0; normal SLE } \\
\text { and FE }\end{array}$ & - & $\begin{array}{c}\text { Month 6, posterior } \\
\text { vitreous } \\
\text { detachment OD }\end{array}$ & $37 ; 0.0 \mathrm{OD}$ \\
\hline $47 / \mathrm{F} \dagger$ & Unilateral & $\begin{array}{l}\text { VA 1.6; SLE, AV cells; } \\
\text { FE, macular FNR }\end{array}$ & $\begin{array}{l}\text { VA 0.0; normal SLE } \\
\text { and FE }\end{array}$ & - & None & $37 ; 1.9 \mathrm{OD}$ \\
\hline 40/M† & Unilateral & $\begin{array}{l}\text { VA 0.0; SLE, AV cells; } \\
\text { FE, peripheral large FNR }\end{array}$ & $\begin{array}{l}\text { VA 0.0; normal SLE } \\
\text { and FE }\end{array}$ & - & None & $37 ; 0.0$ OD \\
\hline $45 / \mathrm{M}$ & Unilateral & $\begin{array}{c}\text { VA 0.0; SLE, AV cells; } \\
\text { FE, PR }\end{array}$ & $\begin{array}{l}\text { VA 0.0; normal SLE } \\
\text { and FE }\end{array}$ & $-s$ & None & $37 ; 0.0 \mathrm{OD}$ \\
\hline 15/M‡ & NA & $\begin{array}{c}\text { VA 0.0; normal SLE and } \\
\text { FE }\end{array}$ & $\begin{array}{l}\text { VA 0.0; normal SLE } \\
\text { and FE }\end{array}$ & $\begin{array}{l}\text { Late ocular involvement; } \\
\text { OD VA } 0.1 \text {; month } 34 \text {, } \\
\text { new peripheral scar }\end{array}$ & None & $34 ; 0.1 \mathrm{OD}$ \\
\hline $28 / \mathrm{F} \ddagger$ & NA & $\begin{array}{c}\text { VA 0.0; normal SLE and } \\
\text { FE }\end{array}$ & $\begin{array}{l}\text { VA 0.0; normal SLE } \\
\text { and FE }\end{array}$ & $\begin{array}{l}\text { Late ocular involvement; } \\
\text { OD VA 0.0; month } 37, \\
\text { peripheral FNR }\end{array}$ & None & $39 ; 0.0$ OD \\
\hline
\end{tabular}

${ }^{*}$ Age represents age at detection of first ocular lesion or scar. AC cells, grading of anterior chamber cells according to Standardization of Uveitis Nomenclature (SUN) working group (29); AV cells, anterior vitreous cells; FE, fundus examination; FNR, focal necrotizing retinochoroiditis, large FNR is >3 disk diameters; IOP, intraocular pressure; KP, keratic precipitates; NA, not applicable; OD, oculus dexter (right eye); OS, oculus sinister (left eye); OU, oculus uterque (both eyes); PR, punctate retinochoroiditis; RC, retinochoroiditis; RD, retinal detachment; SLE, slit-lamp examination; VA, visual acuity (log MAR); -, no recurrence or no new lesion.

†Patients with severe ocular involvement, including binocular, macular, or extensive necrotizing retinochoroiditis ( $>3$ disk diameters).

†Patients with initial normal ophthalmic examination. 
with monocular involvement (log-rank $\mathrm{p}=0.01$; Figure 4) $(24,25)$.

Among patients without ocular involvement at baseline, 2/40 (5\%) had late ocular involvement. A 15 -year-old boy had a new peripheral scar in his right eye (VA 0.1) 34 months after infection, referring a transient VA reduction that started 3 months earlier; the patient recovered spontaneously after a couple of weeks. A 28-year-old woman had a peripheral active lesion in her right eye (VA 0.0) at her 37-month follow-up examination but had no other ocular symptoms (Figure 5).

Overall, 14/52 (27\%) patients had ocular involvement at some point during the study. The rate of ocular involvement was $16 \%$ per person-year (1.3\% per person-month).

\section{Complications and Visual Outcomes}

Among the 16 eyes (15\%) of 12 patients (23\%) with retinochoroiditis at baseline, ocular complications developed in 7 eyes (44\%) of 5 patients (42\%) during follow-up; 2 patients had complications in both eyes. Four
(25\%) eyes had epiretinal membranes develop, detected at 9-, 21-, 22-, and 34-month follow-up visits. One (6\%) eye had rhegmatogeneous retinal detachment at the 27-month follow-up, which required pars plana vitrectomy. One $(6 \%)$ eye had transient intraocular pressure elevation at baseline, and $1(6 \%)$ had posterior vitreous detachment detected at the 6-month follow-up visit.

Among patients with retinochoroiditis at baseline, $4(25 \%)$ eyes among $3(25 \%)$ patients had logMAR VA $>0.3$ at the last follow-up examination. Two eyes had macular involvement at baseline examination and a final VA of 1.9; an epiretinal membrane developed in 1 eye (final VA 0.4), and rhegmatogeneous retinal detachment developed in the other, which underwent pars plana vitrectomy (final VA 0.8).

\section{Discussion}

We investigated ocular involvement of 52 patients with serologically confirmed acute toxoplasmosis acquired in a presumed waterborne outbreak. We described clinical and multimodal imaging findings and determined the prevalence of retinochoroiditis,

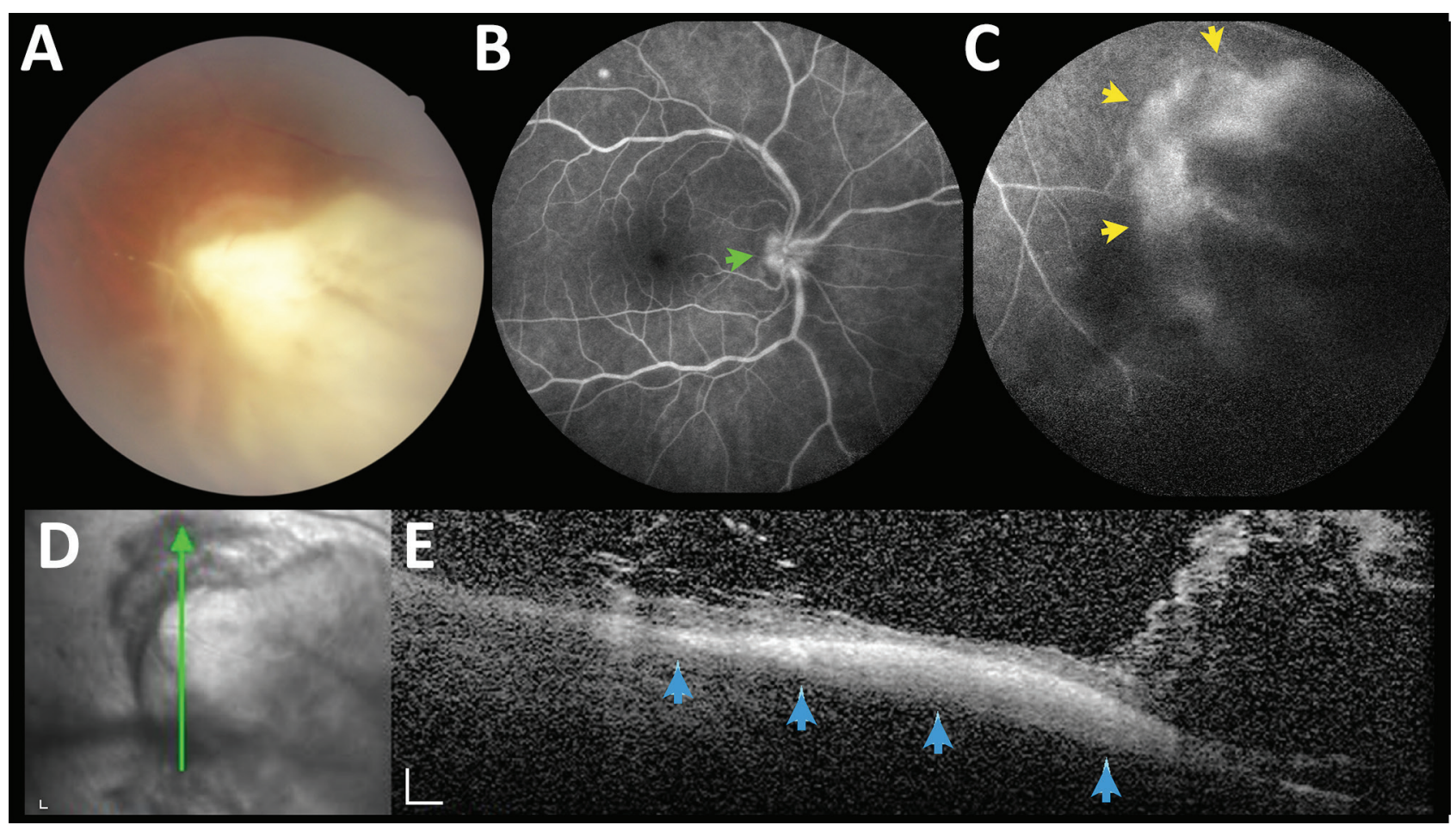

Figure 2. A large necrotizing retinochoroiditis lesion in the right eye, detected in baseline examination (VA 0.5) of a 42-year-old man in a presumed waterborne toxoplasmosis outbreak, Brazil. A) Fundus photograph showing dense focal retinal whitening with indistinct borders, associated with overlying vitreous haze. B) Fundus fluorescein angiography; green arrow indicates hyperfluorescence of optic disc. C) Fundus fluorescein angiography; yellow arrows indicate hyperfluorescence indicating late leakage at the margins of the retinochoroiditis lesion. D) Red-free reflectance showing changes at the level of the active lesion. Green line indicates site of optical coherence tomography scan. E) Spectral-domain optical coherence tomography; blue arrows indicate focal full-thickness hyperreflectivity and disorganization of retinal layers, surrounding retinal thickening, and numerous overlying hyper-reflective dots and bands, indicating exuberant inflammatory vitreous exudation. Scale bars indicate $200 \mu \mathrm{m}$. VA, visual acuity. 


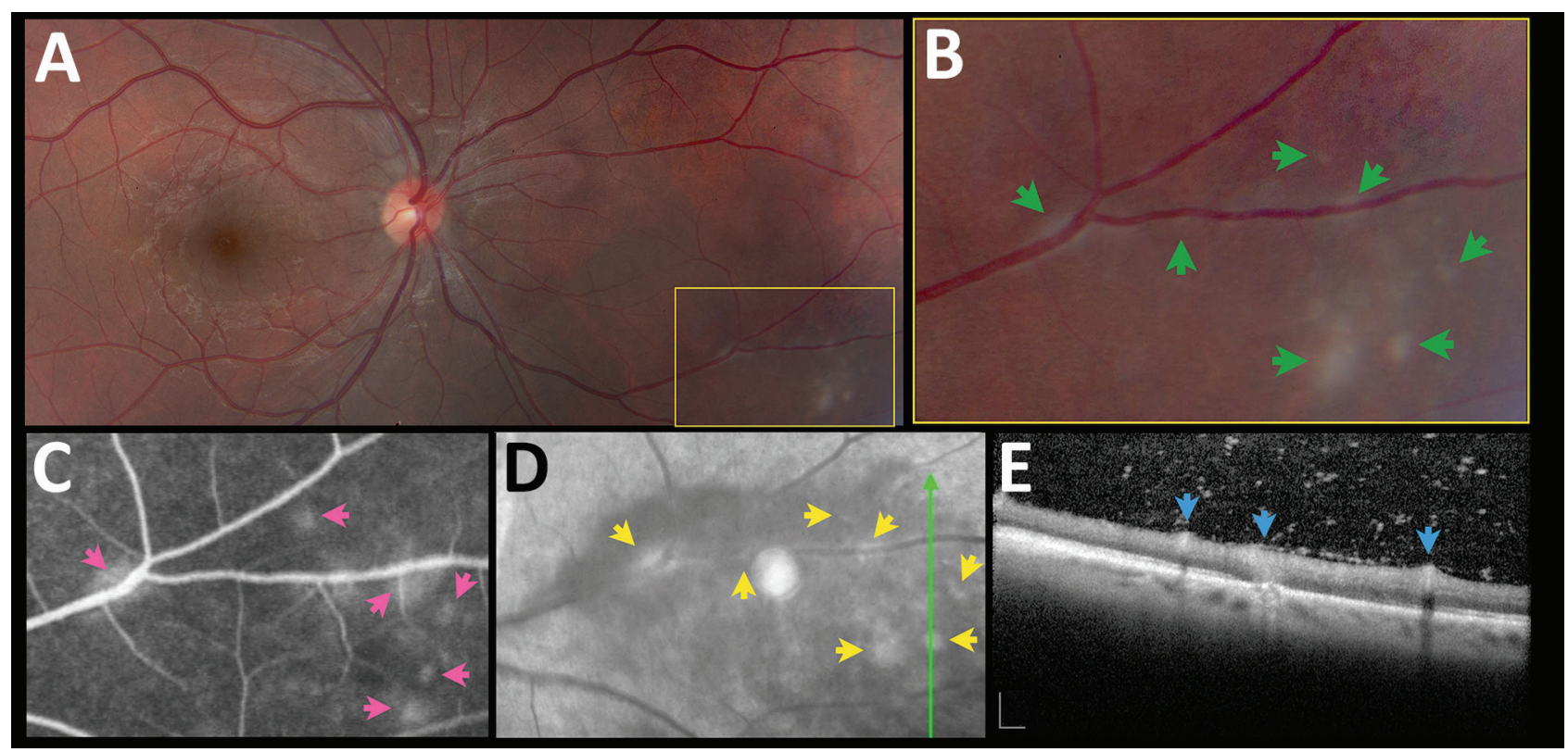

Figure 3. Asymptomatic retinochoroiditis in the right eye, detected in baseline examination (VA 0.0) of a 27-year-old man in a presumed waterborne toxoplasmosis outbreak, Brazil. A) Fundus photograph showing minimal vitreous haze; box indicates enlarged area on B); green arrows indicate multiple subtle and confluent gray-whitish punctate retinal infiltrates. C) Fundus fluorescein angiography. Pink arrows indicate leakage at the site of some of the punctate lesions. D) Fundus fluorescein angiography with red-free reflectance. Green line indicates site of optical coherence tomography scan. Yellow arrows indicate changes in the area of active focuses. E) Spectraldomain optical coherence tomography showing retinal thickening, and numerous overlying hyper-reflective dots. Blue arrows indicate multifocal hyper-reflectivity at the inner retinal layers. Scale bar indicates $200 \mu \mathrm{m}$. VA, visual acuity.

the incidence of recurrences and complications, and analyzed risk factors for ocular involvement.

In addition to the standard pattern of necrotizing retinochoroiditis, multimodal imaging revealed a distinct pattern of punctate retinal infiltrates (Figure 3 ), which might be overlooked if the retina is not examined carefully. This pattern also has been reported in neonates with congenital toxoplasmosis (5) and might represent the result of the primary parasite insult to the retina before a more robust immune response develops.

In this study, $12(23 \%)$ patients displayed toxoplasmic retinochoroiditis at baseline examination; $14(27 \%)$ had ocular involvement at some point during the study (Table 3), a rate of $16 \%$ per personyear. Variable rates of ocular involvement have been reported in toxoplasmosis outbreaks. For instance, risk for ocular involvement was 31\% during the first 10.5 months after the Santa Isabel do Ivaí outbreak in Paraná, Brazil during 2001-2002 (15), and 21\% after a mean follow-up of 114 weeks in an outbreak in Victoria, British Columbia, Canada in $1995(13,14)$.

As expected, eye symptoms, particularly selfreported recently decreased VA and floaters, were associated with ocular involvement, suggesting that clinicians should inquire about symptoms routinely during and after an outbreak. Nevertheless, 2/12 $(16.6 \%)$ patients had retinochoroiditis at baseline in the absence of symptoms, reinforcing the importance of examining the eyes of every patient with confirmed acute $T$. gondii infection.

Older age was frequently associated with a higher risk for ocular involvement at baseline and patients $\geq 40$ years of age at the time of infection had a 5 times greater risk for retinochoroiditis than younger patients. Patients in the subgroup with ocular involvement were much older than patients in the subgroup without ocular involvement, consistent with reports in other studies. In a study from the Netherlands, most patients with serologic evidence of recently acquired ocular toxoplasmosis were older, with a mean age of 50.6 years (26). A study from Brazil found age was a major risk factor for ocular involvement, with higher prevalence in patients $\geq 50$ years of age, and $\approx 50 \%$ of patients $>60$ years of age had ocular involvement (10). Another study from Brazil found that persons $>30$ years of age with recently acquired $T$. gondii infection were more likely to have ocular involvement by the time of study enrollment (9).

At baseline examination, $75 \%(9 / 12)$ of patients with toxoplasmic retinochoroiditis in our study had severe ocular involvement, defined by large (>3 DD) 
necrotizing, macular, or bilateral retinochoroiditis (Figure 2). The median age of the 9 patients with severe ocular involvement (43 years of age) was higher than the median age of the 3 patients with less severe disease ( 31 years of age), but the differences were not statistically significant, probably because of the small number of patients in each subgroup. These findings also are in line with the literature (8), agreeing with 2 previous studies focusing on ocular toxoplasmosis in patients $\geq 50$ years of age (median 67.5 years) in which $22 / 34$ (64.7\%) patients had severe disease, defined as either multiple active lesions, large lesions ( $>3 \mathrm{DD})$, or prolonged disease (duration $>8$ weeks) $(27,28)$. Another possible explanation for the higher rate and severity of ocular involvement in our cohort is involvement of a virulent atypical T. gondii strain. However, this possibility remains elusive because parasite isolation for subsequent genotyping was not successful in the presumably contaminated water source, or in blood samples of patients with serologically confirmed infection (20).

Recurrence of retinochoroiditis was associated with bilateral ocular involvement at initial examination (Figure 4). One possible explanation is that patients with bilateral lesions at initial examination might have had a higher parasite load systemically and in the retina, leading to an increased risk for local reactivation. This finding also might have been associated with some degree of subclinical immune dysfunction in these cases.

The most common complication was epiretinal membrane development in $25 \%$ of eyes with retinochoroiditis, a finding consistent with a transversal study including 248 patients with acquired toxoplasmosis in India, which also reported development of epiretinal membranes at $25.1 \%$ (12). At the last follow-up examination 3/12 (25\%) patients with retinochoroiditis had $\log$ MAR VA $>0.3$, one of them in both eyes. Complications underlying this visual impairment included unilateral macular involvement at baseline in 2 patients (VA 1.9) and other late complications, including 1 eye with an epiretinal membrane (VA 0.4), and the other with a rhegmatogenous retinal detachment (VA 0.8 after pars plana vitrectomy).

In addition to the 4 patients who developed recurrences of retinochoroiditis at 2, 9, 11, 12, or even at 22 months of follow-up, 2 patients without retinochoroiditis had new primary retinal lesions detected $\geq 34$

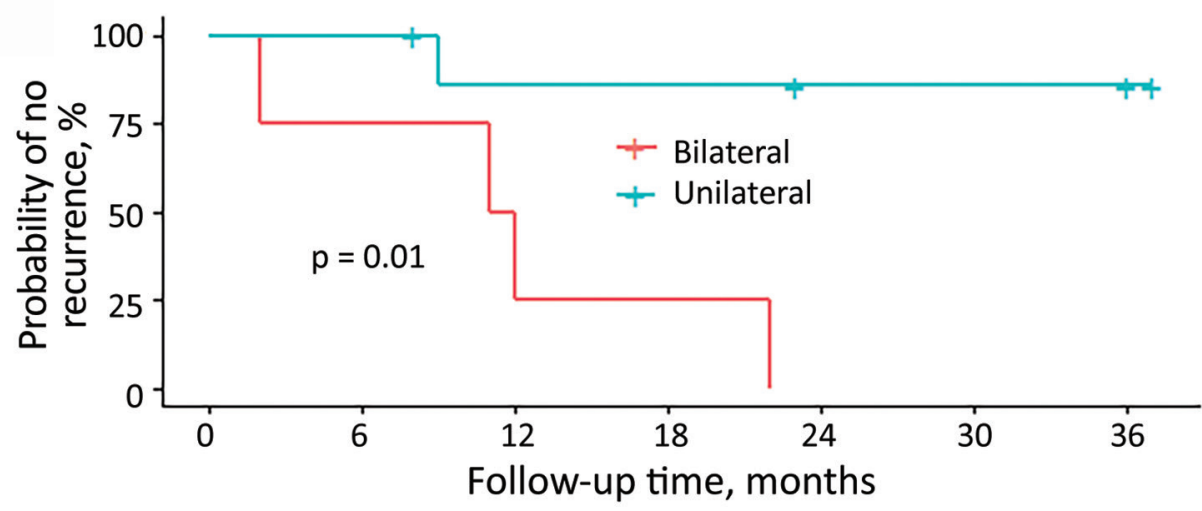

Figure 4. Kaplan-Meier plot showing proportion of patients with toxoplasmic retinochoroiditis at baseline who remain free of recurrence during followup. Bilateral retinochoroidal involvement at baseline was statistically significantly associated with recurrences by log-rank test $(p=0.01)$.

\begin{tabular}{|c|c|c|c|c|c|c|c|}
\hline \multicolumn{8}{|c|}{ No. at risk } \\
\hline Bilateral - & 4 & 3 & 2 & 1 & 0 & 0 & 0 \\
\hline Unilateral- & 8 & 8 & 6 & 6 & 5 & 5 & 5 \\
\hline & 0 & 6 & 12 & 18 & 24 & 30 & 36 \\
\hline
\end{tabular}

\section{Cumulative no. of censoring}

\begin{tabular}{|c|c|c|c|c|c|c|c|}
\hline Bilateral- & 0 & 0 & 0 & 0 & 0 & 0 & 0 \\
\hline Unilateral- & 0 & 0 & 1 & 1 & 2 & 2 & 3 \\
\hline & 0 & 6 & 12 & 18 & 24 & 30 & 36 \\
\hline
\end{tabular}


Figure 5. Asymptomatic late retinochoroiditis in right eye detected in follow-up examination at month 37 (visual acuity 0.0 ) in 28-yearold woman from a presumed waterborne toxoplasmosis outbreak, Brazil. A) Fundus photograph showing focal retinal whitening with indistinct borders. B) Spectral-domain optical coherence tomography showing hyper-reflectivity, disorganization, and thickening OF inner retinal

layers (blue arrow), and numerous overlying hyper-reflective dots at the overlying vitreous and fusiform thickening of underlying choroid (yellow arrows). Scale bars indicate $200 \mu \mathrm{m}$.

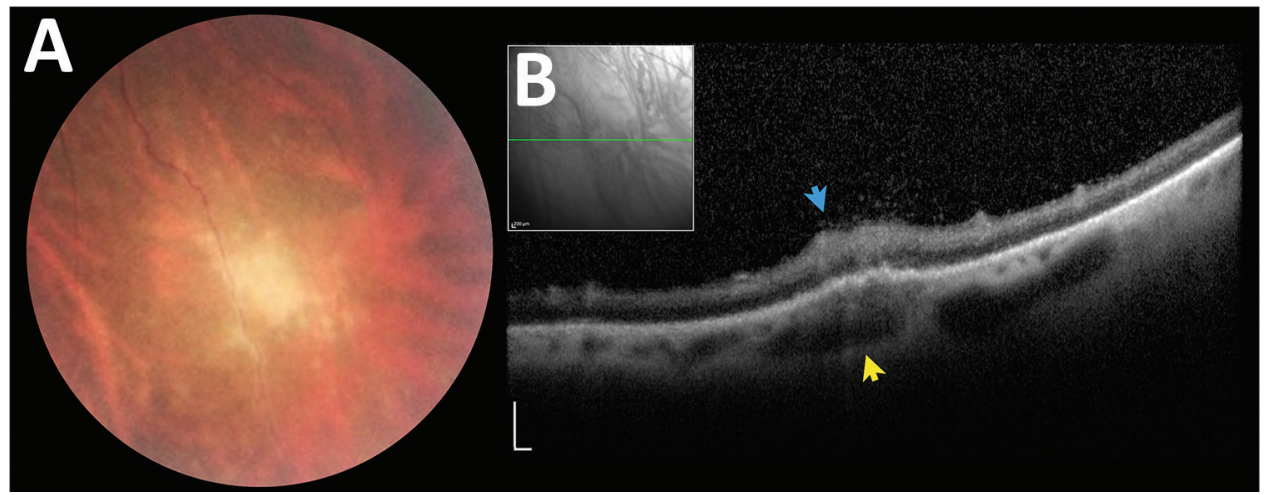

months of follow-up (Figure 5). This finding highlights the need for long-term ophthalmologic followup in patients with postnatally acquired toxoplasmosis, regardless of previous ocular involvement.

This study has some limitations. We only considered symptomatic patients as having suspected cases of acute toxoplasmosis, and that might represent only a small portion of infected persons; several asymptomatic persons probably were not included, and this selection bias might justify, at least in part, the high prevalence of ocular changes. However, selecting for symptomatic cases has been the rule in most investigations of outbreaks of toxoplasmosis because serologic survey of all persons in affected areas is difficult. Finally, incidence calculations were based on few events, especially within subgroups of cases with ocular involvement, and some statistical tests were underpowered, such as the comparison of age in relation to severity of ocular involvement.

Despite the limitations, our study provides objective documentation of ocular changes in the context of a toxoplasmosis outbreak. By using multimodal imaging, we were able to characterize more subtle lesions, such as punctate retinochoroiditis among $33 \%$ of cases with ocular involvement. By comparison, previous reports of ophthalmic assessment of patients during outbreaks mostly were based on indirect ophthalmoscopy alone. Among 52 patients with confirmed infection, $47(90 \%)$ had $\geq 6$ months of follow-up; the median length for follow-up was 36 months, which enabled us to estimate the incidence of new lesions, recurrences, and complications during a relatively long period. We noted a substantial prevalence of early ocular involvement, with recurrences and new lesions occurring up to 39 months after infection. Thus, patients diagnosed with toxoplasmosis should receive long-term ophthalmic follow-up, regardless of initial ocular involvement. In addition, older patients had higher risk for ocular involvement, possibly reflecting age-related changes in the immune system, which could predispose persons $\geq 40$ years of age to more severe disease.

\section{Acknowledgments}

The authors thank the teams from the Brazilian Ministry of Health, especially Juliane Malta; from the State Secretary of Health of Minas Gerais, especially Marcela Lencine Ferraz; and from the Secretary of Health of Gouveia, especially Leticia Miranda, for participation and support.

D.V.V.S. is supported in part by the National Council for Scientific and Technological Development, Brazil (research productivity scholarship no. 313293/2018-0) and received lecture fees from Abbvie.

\section{About the Author}

Dr. Brandão-de-Resende is an engineer and ophthalmologist and recently earned his $\mathrm{PhD}$ at the Federal University of Minas Gerais, Brazil. His research interests encompass uveitis, glaucoma, and applications of machine learning and artificial intelligence in ophthalmology.

\section{References}

1. Montoya JG, Liesenfeld O. Toxoplasmosis. Lancet. 2004; 363:1965-76. https://doi.org/10.1016/S0140-6736(04)16412-X

2. Holland GN. Ocular toxoplasmosis: a global reassessment. Part I: epidemiology and course of disease. Am J Ophthalmol. 2003;136:973-88. https://doi.org/10.1016/ j.ajo.2003.09.040

3. Vasconcelos-Santos DV. Ocular manifestations of systemic disease: toxoplasmosis. Curr Opin Ophthalmol. 2012;23:54350. https://doi.org/10.1097/ICU.0b013e328358bae5

4. Aguirre AA, Longcore T, Barbieri M, Dabritz H, Hill D, Klein PN, et al. The One Health approach to toxoplasmosis: epidemiology, control, and prevention strategies. EcoHealth. 2019;16:378-90. https:/ / doi.org/10.1007/s10393-019-01405-7 
5. Holland GN. Ocular toxoplasmosis: a global reassessment. Part II: disease manifestations and management. Am J Ophthalmol. 2004;137:1-17. https://doi.org/10.1016/ S0002-9394(03)01319-9

6. Vasconcelos-Santos DV, Machado Azevedo DO, Campos WR, Oréfice F, Queiroz-Andrade GM, Carellos EVM, et al. Congenital toxoplasmosis in southeastern Brazil: results of early ophthalmologic examination of a large cohort of neonates. Ophthalmology. 2009;116:2199-2205.e1. https://doi.org/10.1016/j.ophtha.2009.04.042

7. Arantes TE, Silveira C, Holland GN, Muccioli C, Yu F, Jones JL, et al. Ocular involvement following postnatally acquired Toxoplasma gondii infection in southern Brazil: a 28-year experience. Am J Ophthalmol. 2015;159:1002-12.e2. https://doi.org/0.1016/j.ajo.2015.02.015

8. Holland GN. Ocular toxoplasmosis: the influence of patient age. Mem Inst Oswaldo Cruz. 2009;104:351-7. https://doi.org/10.1590/S0074-02762009000200031

9. Dadgostar H, Silveira C, Jones JL, Lee G, Muccioli C, Belfort R Jr., et al. Risk factors for ocular toxoplasmosis among individuals recently infected by Toxoplasma gondii in Southern Brazil. In: Abstracts of the Association for Research in Vision and Ophthalmology annual meeting. Invest Ophthalmol Vis Sci. 2008;49:5529.

10. Portela RW, Bethony J, Costa MI, Gazzinelli A, Vitor RW, Hermeto FM, et al. A multihousehold study reveals a positive correlation between age, severity of ocular toxoplasmosis, and levels of glycoinositolphospholipidspecific immunoglobulin A. J Infect Dis. 2004;190:175-83. https://doi.org/10.1086/421505

11. Bahia-Oliveira LM, Jones JL, Azevedo-Silva J, Alves CC, Oréfice F, Addiss DG. Highly endemic, waterborne toxoplasmosis in north Rio de Janeiro state, Brazil. Emerg Infect Dis. 2003;9:55-62. https:/ / doi.org/10.3201/ eid0901.020160

12. Balasundaram MB, Andavar R, Palaniswamy M, Venkatapathy N. Outbreak of acquired ocular toxoplasmosis involving 248 patients. Arch Ophthalmol. 2010;128:28-32. https://doi.org/10.1001/archophthalmol.2009.354

13. Bowie WR, King AS, Werker DH, Isaac-Renton JL, Bell A, Eng SB, et al.; The BC Toxoplasma Investigation Team. Outbreak of toxoplasmosis associated with municipal drinking water. Lancet. 1997;350:173-7. https:/ / doi. org/10.1016/S0140-6736(96)11105-3

14. Burnett AJ, Shortt SG, Isaac-Renton J, King A, Werker D, Bowie WR. Multiple cases of acquired toxoplasmosis retinitis presenting in an outbreak. Ophthalmology. 1998;105:1032-7. https:/ / doi.org/10.1016/S0161-6420(98)96004-3

15. Silveira C, Muccioli C, Holland GN, Jones JL, Yu F, de Paulo A, et al. Ocular involvement following an epidemic of Toxoplasma gondii infection in Santa Isabel do Ivai, Brazil. Am J Ophthalmol. 2015;159:1013-21e3. https:/ / doi.org/10.1016/j.ajo.2015.02.017

16. Teutsch SM, Juranek DD, Sulzer A, Dubey JP, Sikes RK. Epidemic toxoplasmosis associated with infected cats.
N Engl J Med. 1979;300:695-9. https://doi.org/10.1056/ NEJM197903293001302

17. Perkins ES. Ocular toxoplasmosis. Br J Ophthalmol. 1973;57:1-17. https://doi.org/10.1136/bjo.57.1.1

18. Benenson MW, Takafuji ET, Lemon SM, Greenup RL, Sulzer AJ. Oocyst-transmitted toxoplasmosis associated with ingestion of contaminated water. N Engl J Med. 1982; 307:666-9. https://doi.org/10.1056/NEJM198209093071107

19. Akstein RB, Wilson LA, Teutsch SM. Acquired toxoplasmosis. Ophthalmology. 1982;89:1299-302. https:/ / doi.org/10.1016/S0161-6420(82)34629-1

20. Malta JMAS, Cabral CM, Nóbrega AA, Leite PL, de Souza Alves RM, Almeida SML, et al. Outbreak of toxoplasmosis in the municipality of Gouveia, Minas Gerais [in Portuguese]. J Health Biol Sci. 2019;7:233-41. https:/ / doi. org/10.12662/2317-3076jhbs.v7i3.2375.p233-241.2019

21. R: a language and environment for statistical computing. 2017; Vienna, Austria: R Foundation for Statistical Computing [cited 2020 Feb 2]. https:/ / www.r-project.org

22. Becker S. A comparison of maximum likelihood and Jewell's estimators of the odds ratio and relative risk in single $2 \times 2$ tables. Stat Med. 1989;8:987-96. https:// doi.org/10.1002/ sim.4780080809

23. Jabs DA. Improving the reporting of clinical case series. Am J Ophthalmol. 2005;139:900-5. https:// doi.org/10.1016/ j.ajo.2004.12.009

24. Harrington DP, Fleming TR. A class of rank test procedures for censored survival data. Biometrika. 1982;69:553-66. https://doi.org/10.1093/ biomet/69.3.553

25. Mantel N. Evaluation of survival data and two new rank order statistics arising in its consideration. Cancer Chemother Rep. 1966;50:163-70.

26. Bosch-Driessen LE, Berendschot TT, Ongkosuwito JV, Rothova A. Ocular toxoplasmosis: clinical features and prognosis of 154 patients. Ophthalmology. 2002;109:869-78. https:// doi.org/10.1016/S0161-6420(02)00990-9

27. Labalette P, Delhaes L, Margaron F, Fortier B, Rouland JF. Ocular toxoplasmosis after the fifth decade. Am J Ophthalmol. 2002;133:506-15. https://doi.org/10.1016/ S0002-9394(02)01324-7

28. Johnson MW, Greven GM, Jaffe GJ, Sudhalkar H, Vine AK. Atypical, severe toxoplasmic retinochoroiditis in elderly patients. Ophthalmology. 1997;104:48-57. https://doi.org/ 10.1016/S0161-6420(97)30362-5

29. Jabs DA, Nussenblatt RB, Rosenbaum JT; Standardization of Uveitis Nomenclature (SUN) Working Group.

Standardization of uveitis nomenclature for reporting clinical data. Results of the First International Workshop. Am J Ophthalmol. 2005;140:509-16. https://doi.org/10.1016/ j.ajo.2005.03.057

Address for correspondence: Daniel Vitor Vasconcelos-Santos, Av. Alfredo Balena 190, Sala 199, Belo Horizonte, MG 30190-090, Brazil.email: dvitor@ufmg.br 